\title{
Sling Revision/Removal for Mesh Erosion and Urinary Retention: Long-term Risk and Predictors
}

\author{
Michele Jonsson Funk, PhD ${ }^{1,2}$, Nazema Y. Siddiqui, MD, MHSc ${ }^{3}$, Virginia Pate, MS $^{1}$, Cindy \\ L. Amundsen, $\mathbf{M D}^{3}$, and Jennifer M. Wu, MD, $\mathbf{M P H}^{3}$ \\ ${ }^{1}$ Department of Epidemiology, Gillings School of Global Public Health, University of North \\ Carolina at Chapel Hill, Chapel Hill, NC \\ ${ }^{2}$ Center for Women's Health Research, University of North Carolina at Chapel Hill, Chapel Hill, \\ $\mathrm{NC}$ \\ ${ }^{3}$ Division of Urogynecology, Department of Obstetrics and Gynecology, Duke University, Durham, \\ $\mathrm{NC}$
}

\begin{abstract}
Objectives-To estimate the long-term risk of sling revision/removal after an initial sling and to assess indications (mesh erosion and urinary retention) and predictors of sling revision/removal.

Study Design-Using a population-based cohort of commercially insured individuals, we identified women $\geq 18$ who underwent a sling (CPT 57288) between 2001-2010 and any subsequent sling revision/removal (CPT 57287). We estimated the cumulative risk of revision/ removal annually and evaluated predictors of sling revision/removal using Kaplan-Meier survival curves and Cox proportional hazards models, respectively.
\end{abstract}

Results-We identified 188,454 eligible women who underwent an index sling. The 9-year cumulative risk of sling revision/removal was 3.7\% (95\% CI 3.5, 3.9). At one year, this risk was already $2.2 \%$ and then increased to $3.2 \%$ at four years before plateauing. Regarding the indication for the sling revision/removal, a greater proportion was due to mesh erosion compared to urinary retention, with a 9-year risk of $2.5 \%(95 \%$ CI $2.3,2.6)$ for mesh erosion versus $1.3 \%$ (95\% CI 1.2, 1.4) for urinary retention. Age had an effect on revision/removal rates for both mesh erosion and urinary retention, with the higher risks among those aged 18-29. The risk of revision/removal for mesh erosion and urinary retention was also elevated among women who had a concomitant anterior or apical prolapse procedure.

Conclusions-In this population-based analysis, the 9-year risk of sling revision/removal was relatively low at $3.7 \%$, with $60 \%$ of revisions/removals due to mesh erosion.

\footnotetext{
() 2012 Mosby, Inc. All rights reserved.

Corresponding Author: Jennifer M. Wu, MD, MPH, Duke University Medical Center, Box 3192, 5324 McFarland Avenue, Suite 310, Durham, North Carolina 27707, Work: (919) 401-1006, Home: (919) 452-4577, Fax: (919) 401-1034, jennifer.wu@ duke.edu.

Publisher's Disclaimer: This is a PDF file of an unedited manuscript that has been accepted for publication. As a service to our customers we are providing this early version of the manuscript. The manuscript will undergo copyediting, typesetting, and review of the resulting proof before it is published in its final citable form. Please note that during the production process errors may be discovered which could affect the content, and all legal disclaimers that apply to the journal pertain.

Disclosure: None of the authors have any relevant conflicts of interest

The content is solely the responsibility of the authors and does not necessarily represent the official views of the Agency for Healthcare Research and Quality.

Accepted as oral poster presentation at the 33rd Annual Meeting of the American Urogynecologic Society, Chicago, IL, October 3-6, 2012.
} 


\section{Keywords}

mesh erosion; sling; sling removal; sling revision; urinary retention

\section{INTRODUCTION}

Slings represent the most common surgery for stress urinary incontinence (SUI) and are now considered the gold standard procedure. ${ }^{1,2}$ Historically, "slings" referred to bladder neck slings, ${ }^{3}$ which remain an effective surgery for SUI. ${ }^{4}$ However, midurethral slings now dominate the surgical management of stress incontinence. The uptake of the midurethral synthetic mesh sling has increased dramatically since the introduction of the Tension-free Vaginal Tape ${ }^{\circledR}$ in the United States in $1998 .{ }^{5}$ Over the last decade, the retropubic midurethral sling has been modified, and the category of midurethral slings now includes transobturator slings as well as "mini-slings."

The adoption of the midurethral sling was supported by level I evidence, which demonstrated similar five-year effectiveness of retropubic midurethral slings and Burch colposuspensions, ${ }^{6}$ the prior gold standard SUI procedure. Furthermore, randomized trials have reported equivalence between retropubic and transobturator slings at one year. ${ }^{7,8}$ Although high quality data from randomized trials exist regarding long-term effectiveness of midurethral slings, long-term population-based data are limited regarding the need for repeat surgery to manage complications such as mesh erosion or urinary retention. The best available data on complications suggest that the risk of sling revision/removal for either mesh erosion or retention is fairly low, ranging from approximately $1-3 \%, 9$ and $0.6-$ $1.2 \%,{ }^{8,9}$ respectively. To date, the largest observational cohort reported on fewer than 4,000 sling procedures followed for a maximum of 21 months. ${ }^{9}$ Thus, long-term follow-up of patients treated in 'real-world' clinical settings are needed to further characterize the rates of repeat surgery to manage complications such as mesh erosion or urinary retention.

The recent FDA notification regarding vaginal mesh for prolapse ${ }^{10}$ has simultaneously increased the attention directed at midurethral slings, as these procedures involve synthetic mesh placed vaginally. While the FDA notification specifically addresses vaginal mesh prolapse procedures, an update on January 4, 2012 stated that "the FDA continues to evaluate the effects of using surgical mesh for treatment of urine leakage during moments of physical activity (stress urinary incontinence) and will provide updates on this webpage at a later date." Thus, the FDA verdict regarding mesh slings for SUI is pending.

For relatively new procedures, it is critical to conduct long-term outcome assessments. For the midurethral sling, an important outcome to assess is the risk of a sling revision or removal to manage complications such as a mesh erosion or urinary retention. Given the FDA emphasis on evaluating medical devices involving vaginal mesh and the limited, longterm, population-based data regarding slings, the objective of this study was to estimate the long-term risk of sling revision/removal after an initial sling in a large, population-based cohort. Our secondary objective was to assess the indication for sling revision/removal (mesh erosion and urinary retention) as well as predictors of revision/removal.

\section{MATERIALS AND METHODS}

\section{Data Source}

We utilized the Thomson Reuters MarketScan ${ }^{\circledR}$ Commercial Claims and Encounters (CC\&E) and Medicare Supplemental Coordination of Benefits database from 2001-2010 (copyright $\odot 2011$ Thomson Healthcare Incorporated Inc). ${ }^{11}$ This database contains de- 
identified, individual-level healthcare utilization and enrollment data for inpatient, outpatient, and pharmacy visits from approximately 100 employer-based plans in the United States. These de-identified data represent the medical experience of privately-insured employees, retirees, covered spouses and dependents. This database has been rigorously evaluated and is valid and reliable. ${ }^{12}$ Individuals can be followed longitudinally using encrypted unique identification numbers, and enrollment data allowed us to determine which individuals have insurance coverage at any point in time. This database provided information on 44.8 million women aged 18 years and older between the years 2001 to 2010. This study was determined to be exempt from further review by the Institutional Review Board at the University of North Carolina at Chapel Hill.

\section{Inclusion Criteria and Index Sling}

The population of interest included all women aged 18 years and older from 2001 to 2010 . The first, or index, sling was identified for each woman, based on current procedural terminology (CPT) code 57288. We included women with at least 90 days of continuous enrollment prior to the procedure. Those with a diagnosis of a urethral diverticulum (International Classification of Diseases, $9^{\text {th }}$ revision, clinical modification (ICD-9-CM) code 619.0) or any urinary-genital tract fistula (codes 599.1 and 599.2) in the 90 days prior to the index surgery were excluded. If an additional SUI procedure (i.e. a different type of SUI surgery such as a Burch colposuspension) was coded on the same date as the sling, these individuals were excluded. The location for the procedure was also assessed, whether inpatient or outpatient. If both an inpatient and outpatient procedure claim occurred on the same service date, we preferentially included the inpatient procedure.

\section{Sling Revision/Removal}

After the index sling, the first subsequent sling revision/removal was identified using CPT code 57287. If another SUI surgery was performed after the index sling (i.e. another sling, Burch colposuspension, bulking agent, etc...), the outcomes of these individuals were censored at that surgery date, as we were unable to determine whether any subsequent revision/removal was secondary to the index sling or the repeat SUI procedure. Otherwise, individuals were censored at the earliest disenrollment or on December 31, 2010.

In addition to identifying sling revision/removals, we assessed the indication for this procedure based on ICD-9-CM codes for mesh erosion (996.30, 996.39, 996.59, 996.60, 996.65, 996.69, 996.70, 996.76, 996.79, 939.0, 939.2, and 939.9) and urinary retention (596.0, 598.1, 598.2, 598.8, 598.9, 599.6, 599.69, 788.2, 788.21, 788.29, 788.61, 788.62, and 788.65). We did not utilize 629.3 (Complication of implanted vaginal mesh and other prosthetic materials), 629.31 (erosion of implanted vaginal mesh) or 629.32 (exposure of implanted vaginal mesh), as these ICD-9 codes were not released until $2011,{ }^{13}$ and, thus, were not applicable during our study period. It is important to note that the diagnoses of mesh erosion and/or urinary retention were not mutually exclusive; thus, both mesh erosion and urinary retention could be associated with a single sling revision/removal procedure. For the indication-specific outcome definitions, individuals were censored if they had a revision/ removal for another indication.

\section{Statistical Analysis}

Descriptive statistics were used to characterize the population of women who underwent an index sling procedure. Kaplan-Meier survival curves were used to estimate the cumulative incidence (with 95\% confidence intervals) of sling revision/removal at 3 months, 6 months, and annually through 9 years of follow-up. We also estimated the cumulative incidence of sling revision/removal for mesh erosion and urinary retention separately. In order to explore the potential for differences in the risk of these outcomes due to the year when the index 
sling was placed, we also compared the cumulative risk at one year after the index sling, stratified by calendar year in which the index sling was performed.

We used Cox proportional hazards models to estimate the adjusted hazard ratio (adjHR) of the following: 1) sling revision/removal separately by decade of age $(18-29,30-39,40-49$, $50-59,60-69$ ) at the time of the index surgery compared to those 70 years of age and older; 2) inpatient versus outpatient procedures; 3) concomitant hysterectomy; and 4) concomitant prolapse procedures. In order to further examine the possibility of different effects of these risk factors on revision/removal for mesh erosion and urinary retention, we also estimated adjHRs separately for each of these outcomes. We estimated $95 \%$ confidence intervals on all effect estimates. Statistical analyses were performed using SAS, v9.2 (SAS Institute, Cary, NC).

\section{RESULTS}

Of the 44.8 million women aged 18 years or older from 2001-2010, there were 188,454 index sling procedures. The median age of women undergoing surgery was 53 years (interquartile range 45,61 ), and approximately $60 \%$ of these procedures were performed in women aged 40-59 years of age (Table 1). Table 1 also depicts the year in which the index sling was performed and illustrates that a higher proportion of surgeries were done in the latter years reflecting an increase in the database's enrolled population. Because the majority of procedures were performed in the latter portion of the decade, there are relatively more procedures with shorter time intervals of follow-up (Table 1). Nonetheless, we have four or more years of follow-up on 25,219 individuals, and more than eight years on 1,864 individuals. A majority (67\%) of the procedures was performed on an outpatient basis, and the South had the largest proportion of sling procedures (49\%). Concomitant hysterectomy and concurrent prolapse procedures were also common (Table 1).

The cumulative incidence of sling revision/removal for any indication was 3.7\% (95\%CI $3.5,3.9$ ) at nine years of follow-up (Table 2). At one year of follow-up, this risk was $2.2 \%$ and then increased to $3.2 \%$ at four years before plateauing. Thus, a majority of sling revision/removals occurred within the first few years after the index surgery. Regarding the indication for the sling revision/removal, a greater proportion was due to mesh erosion compared to urinary retention, with a nine-year risk of $2.5 \%(95 \% \mathrm{CI} 2.3,2.6)$ for mesh erosion versus $1.3 \%(95 \% \mathrm{CI} 1.2,1.4)$ for urinary retention. Focusing on mesh erosion, the risk of revision/removal increased from $1.3 \%$ at one year to $2.1 \%$ at four years before leveling off. For urinary retention, the risk was $0.9 \%$ at one year and then remained fairly stable afterwards.

In order to further evaluate possible changes over time in the risk of revision/removal for mesh erosion and urinary retention, we estimated the one-year risk for sling revision/ removal by indication for each calendar year (Figure 1). This analysis was prompted because the type of midurethral slings performed (i.e. retropubic midurethral slings versus transobturator slings versus "mini-slings") may have changed during the study period. While the one-year cumulative risk of sling revision/removal for any indication remained fairly stable over the study period, there was an increase in the one-year risk of revision/removal for mesh erosion and a decrease in the risk of surgery for retention over the study period (Figure 1).

We also evaluated predictors of sling revision/removal based on indication using Cox proportional hazards models. For revision/removal due to mesh erosion, all women aged 1869 were at higher risk compared to those age 70 years and older, with the highest risk among those 18-39 (Table 3). The risk of revision/removal for mesh erosion was also elevated 
among women who had a concomitant anterior (HR 1.18, 95\%CI 1.08, 1.29) or apical (HR $1.24,95 \% \mathrm{CI} 1.10,1.41)$ prolapse procedure, but not among those who had a posterior prolapse procedure (HR 1.06, 95\%CI 0.91, 1.24). Women who had a concurrent hysterectomy had a lower risk of revision/removal for mesh erosion (HR $0.81,95 \%$ CI 0.73 , $0.90)$.

For sling revision/removal due to urinary retention, women aged 18-29 (HR 1.91, 95\% CI $1.22,2.99)$ had a significantly higher risk than women aged 70 and older. Inpatient procedures were also associated with a higher risk of sling revision/removal for retention compared to outpatient procedures (HR 1.18, 95\% CI 1.06, 1.32). Women who had a concomitant anterior (HR 1.22, 95\%CI 1.09, 1.36) or apical (HR 1.43, 95\%CI 1.25, 1.64) prolapse procedure were also at higher risk of subsequent revision/removal for retention compared to those who did not. Concomitant posterior prolapse procedures and hysterectomy were not associated with any change in the risk of revision/removal for urinary retention.

\section{COMMENT}

In this large, population-based cohort of 188,454 adult women who underwent an index sling, the risk of sling revision/removal was relatively low at $3.7 \%$ at nine years of followup. The majority of revisions/removals occurred within four years after the index surgery. Mesh erosion, rather than urinary retention, was the indication for a majority of these procedures. We also found that risk factors differed for the two primary indications for revision/removal with a stronger effect of age on mesh erosion.

Our findings regarding the risk of sling revision/removal are consistent with the existing literature. In the landmark trial of Tension-free Vaginal Tape (TVT) versus Burch colposuspension, Ward et al. reported that 1/170 (0.6\%) TVTs had obstructed voiding requiring sling revision and 5/170 (2.9\%) had erosion/extrusion. ${ }^{6}$ Other randomized trials of retropubic versus transobturator slings revealed a $2.7 \%$ rate of voiding dysfunction requiring surgery, ${ }^{7}$ and rates of erosions and/or exposures ranged from $1.8-3.5 \%$, although not all of these required surgery. ${ }^{7,8}$ Prior to our study, the largest population-based study evaluated 3,747 slings over a 21 -month time period and found that the rate of sling loosening or transection was $1.2 \%$ for retropubic procedures, $1.9 \%$ for transobturator slings and $1.3 \%$ for single-incision surgeries. ${ }^{9}$ The risk of surgery for vaginal mesh exposure was $0.9 \%$ and $1.0 \%$ for retropubic and transobturator procedures, respectively. ${ }^{9}$ While several systematic reviews and meta-analyses have been performed regarding midurethral slings, ${ }^{14-18}$ the cumulative number of subjects in these studies remains significantly lower than our study population. We extend the literature in that we evaluated over 188,000 index slings with annual rates for sling revision/removal based on indication through nine years of follow-up. Our results suggest that the relatively low rate of sling revision/removal in the short-term does not increase dramatically over the first nine years after surgery.

Our study revealed interesting and surprising findings regarding predictors for sling revision/removal. Our results showed a strong effect of age on the risk of sling revision/ removal for mesh erosion, with the highest risk among younger women. This was surprising given that urogenital atrophy occurs in older populations, leading to poorer tissue quality with a presumably higher risk for mesh erosion. It is possible that younger women were more sexually active, and sexual activity could be a risk factor for mesh erosion.

Alternatively, younger women who are more sexually active may have been more likely to detect mesh erosion and to opt for surgical management. Unfortunately, because slings of all types were coded using CPT code 57288, we were unable to determine which type of sling was associated with greater risk of mesh erosion. 
Regarding sling revision/removal for urinary retention, we found that the youngest age group (women 18-29), were at highest risk for repeat surgery, although the strong gradient of risk by age was not present. These results were also surprising in that older age groups are more likely to suffer from impaired detrusor contractility, ${ }^{19}$ which could lead to a higher risk of urinary retention after slings. Perhaps younger women were less tolerant of irritative voiding symptoms or de novo urge incontinence, and therefore had a lower threshold to undergo surgical management in attempts to remedy these symptoms. Other variables associated with sling revision/removal for urinary retention and mesh erosion included concurrent anterior or apical prolapse procedures. It is possible that the changes in pelvic support and anatomy associated with anterior and apical prolapse exacerbated urinary retention and compromised healing due to the additional vaginal incisions.

We also found that there were differences in the one-year risk of sling revision/removal based on the year in which the index sling was performed. The risk of surgery for urinary retention decreased from 2001 to 2010 . We hypothesize that as surgeons became more familiar with how to perform slings, their technique improved. Also, the more recent introduction of the transobturator and mini-slings may be associated with a lower risk of surgery for retention, as these slings are less compressive around the urethra. ${ }^{20}$ On the other hand, the risk of sling revision/removal for mesh erosion increased over the study period. It is possible that transobturator slings and certain mini-slings leave more mesh traversing the vaginal space which could increase the risk for mesh erosion. In addition, the FDA 2008 notification may have led to a higher risk of sling revision/removal for this indication, as it heightened awareness of mesh erosion as a possible sling complication among both patients and providers. ${ }^{21}$

This study provides comprehensive data on over 188,000 index sling procedures with longterm follow-up over nine years in a nationally representative, population-based cohort. One unique aspect of these healthcare claims data was that we can accurately account for individual contributions to follow-up time with complete capture of subsequent clinical care as long as an individual continued to have insurance coverage. For example, even if a subject with a sling complication did not follow-up at the same institution in which the initial sling was performed, follow-up data regarding sling revision/removal was available. Another benefit of this database was that we were able to follow patients beyond the age of 65 years when they transitioned into Medicare by virtue of the Medicare supplemental data.

This study was limited by the fact that the database only included privately-insured individuals, and thus, the results may not be generalizable to uninsured or underinsured individuals. Furthermore, detailed sociodemographic and clinical data such as race, physical examination findings, such as body mass index, and severity of urinary incontinence were not available. We were also limited by the specificity of CPT codes in the database. Currently, there is one encompassing CPT code for all sling procedures, code 57288, which includes traditional bladder neck, retropubic midurethral slings, transobturator slings, and mini-slings. The proposed FDA rule that would require unique device identifiers (UDIs) will make it possible to distinguish specific types of slings, but it will be many years before longterm outcome data will be available for surgeries in which the UDI has been recorded. ${ }^{22}$ Lastly, we acknowledge that our data does not represent the overall risk of mesh erosion after a sling, as some erosions may have been managed conservatively in the office and some erosions managed surgically may have been coded by a different CPT (i.e. 57295 revise vaginal graft via vaginal approach) and not CPT 57287, which indicates a sling revision/removal.

In conclusion, after an index sling procedure, the risk of sling revision/removal for either mesh erosion or urinary retention is $<4 \%$ over nine years of follow-up. The majority of 
these sling revisions/removals were due to mesh erosion rather than urinary retention. Age, slings performed with concomitant prolapse surgery, and the calendar year of the index sling were associated with the risk of sling revision/removal. Although the FDA evaluation for slings is still pending, ${ }^{10}$ these long-term results in a large, population-based cohort are reassuring. However, future studies should aim to study specific sling types in a large cohort of women with long-term follow-up.

\section{Acknowledgments}

This project was supported by grant number K02HS017950 from the Agency for Healthcare Research and Quality (AHRQ) (M.J.F) and grant number K23HD068404 from the Eunice Kennedy Shriver National Institute of Child Health \& Human Development (J.M.W).

\section{REFERENCES}

1. Oliphant SS, Wang L, Bunker CH, Lowder JL. Trends in stress urinary incontinence inpatient procedures in the United States, 1979-2004. Am J Obstet Gynecol. 2009; 200:521, e1-e6. [PubMed: 19375571]

2. Jonsson Funk M, Levin PJ, Wu JM. Trends in the surgical management of stress urinary incontinence. Obstet Gynecol. 2012; 119:845-851. [PubMed: 22433349]

3. Bezerra CA, Bruschini H, Cody DJ. Traditional suburethral sling operations for urinary incontinence in women. Cochrane Database Syst Rev. 2005 CD001754.

4. Albo ME, Richter HE, Brubaker L, et al. Burch colposuspension versus fascial sling to reduce urinary stress incontinence. N Engl J Med. 2007; 356:2143-2155. [PubMed: 17517855]

5. FDA. 1998 Jan 28. 510(K) Number K974098.

6. Ward KL, Hilton P. Tension-free vaginal tape versus colposuspension for primary urodynamic stress incontinence: 5-year follow up. Bjog. 2008; 115:226-233. [PubMed: 17970791]

7. Richter HE, Albo ME, Zyczynski HM, et al. Retropubic versus transobturator midurethral slings for stress incontinence. N Engl J Med. 2010; 362:2066-2076. [PubMed: 20479459]

8. Barber MD, Kleeman S, Karram MM, et al. Transobturator tape compared with tension-free vaginal tape for the treatment of stress urinary incontinence: a randomized controlled trial. Obstet Gynecol. 2008; 111:611-621. [PubMed: 18310363]

9. Nguyen JN, Jakus-Waldman SM, Walter AJ, White T, Menefee SA. Perioperative complications and reoperations after incontinence and prolapse surgeries using prosthetic implants. Obstet Gynecol. 2012; 119:539-546. [PubMed: 22353951]

10. FDA Safety Communication. [Accessed on June 12, 2012] Update on serious complications associated with transvaginal placement of surgical mesh for pelvic organ prolapse. Issued on July 13, 2011. (at http://www.fda.gov/medicaldevices/safety/alertsandnotices/ucm262435.htm).

11. Source: RED BOOK® and MarketScan ${ }^{\circledR}$ are registered trademarks of Thomson Reuters. (Healthcare) Inc.; Thomson Reuters MarketScan ${ }^{\circledR}$ Commercial Claims and Encounters Database, 2000-2009. (at http://thomsonreuters.com/products_services/healthcare/healthcare_products/ pharmaceuticals/mktscan_res_db/)

12. Hansen LG, Chang S. Health Research Data for the Real World: The Thomson Reuters MarketScan Databases. White paper. 2011

13. Centers for Disease Control and Prevention. [Retrieved June 26, 2012] Classification of Diseases. 2011 Oct. Conversion Table of New ICD-9-CM Codes, Available at http://www.cdc.gov/nchs/ data/icd9/CNVTB12.pdf.

14. Novara G, Artibani W, Barber MD, et al. Updated systematic review and meta-analysis of the comparative data on colposuspensions, pubovaginal slings, and midurethral tapes in the surgical treatment of female stress urinary incontinence. Eur Urol. 2010; 58:218-238. [PubMed: 20434257]

15. Novara G, Galfano A, Boscolo-Berto R, et al. Complication rates of tension-free midurethral slings in the treatment of female stress urinary incontinence: a systematic review and meta-analysis of 
randomized controlled trials comparing tension-free midurethral tapes to other surgical procedures and different devices. Eur Urol. 2008; 53:288-308. [PubMed: 18031923]

16. Sung VW, Schleinitz MD, Rardin CR, Ward RM, Myers DL. Comparison of retropubic vs transobturator approach to midurethral slings: a systematic review and meta-analysis. Am J Obstet Gynecol. 2007; 197:3-11. [PubMed: 17618742]

17. Ogah J, Cody JD, Rogerson L. Minimally invasive synthetic suburethral sling operations for stress urinary incontinence in women. Cochrane Database Syst Rev. 2009 CD006375.

18. Abdel-Fattah M, Ford JA, Lim CP, Madhuvrata P. Single-incision mini-slings versus standard midurethral slings in surgical management of female stress urinary incontinence: a meta-analysis of effectiveness and complications. Eur Urol. 2011; 60:468-480. [PubMed: 21621321]

19. Taylor JA 3RD, Kuchel GA. Detrusor underactivity: Clinical features and pathogenesis of an underdiagnosed geriatric condition. J Am Geriatr Soc. 2006; 54:1920-1932. [PubMed: 17198500]

20. Latthe PM, Foon R, Toozs-Hobson P. Transobturator and retropubic tape procedures in stress urinary incontinence: a systematic review and meta-analysis of effectiveness and complications. Bjog. 2007; 114:522-531. [PubMed: 17362484]

21. [Accessed on June 12, 2012] FDA Public Health Notification: Serious Complications Associated with Transvaginal Placement of Surgical Mesh in Repair of Pelvic Organ Prolapse. Issued: October 20, 2008. (at http://www.fda.gov/medicaldevices/safety/alertsandnotices/ publichealthnotifications/ucm061976.htm).

22. FDA. [Accessed July 27, 2012] Unique Device Identification (UDI) Proposed Rule. at http:// www.fda.gov/MedicalDevices/ResourcesforYou/Industry/ucm310872.htm). 


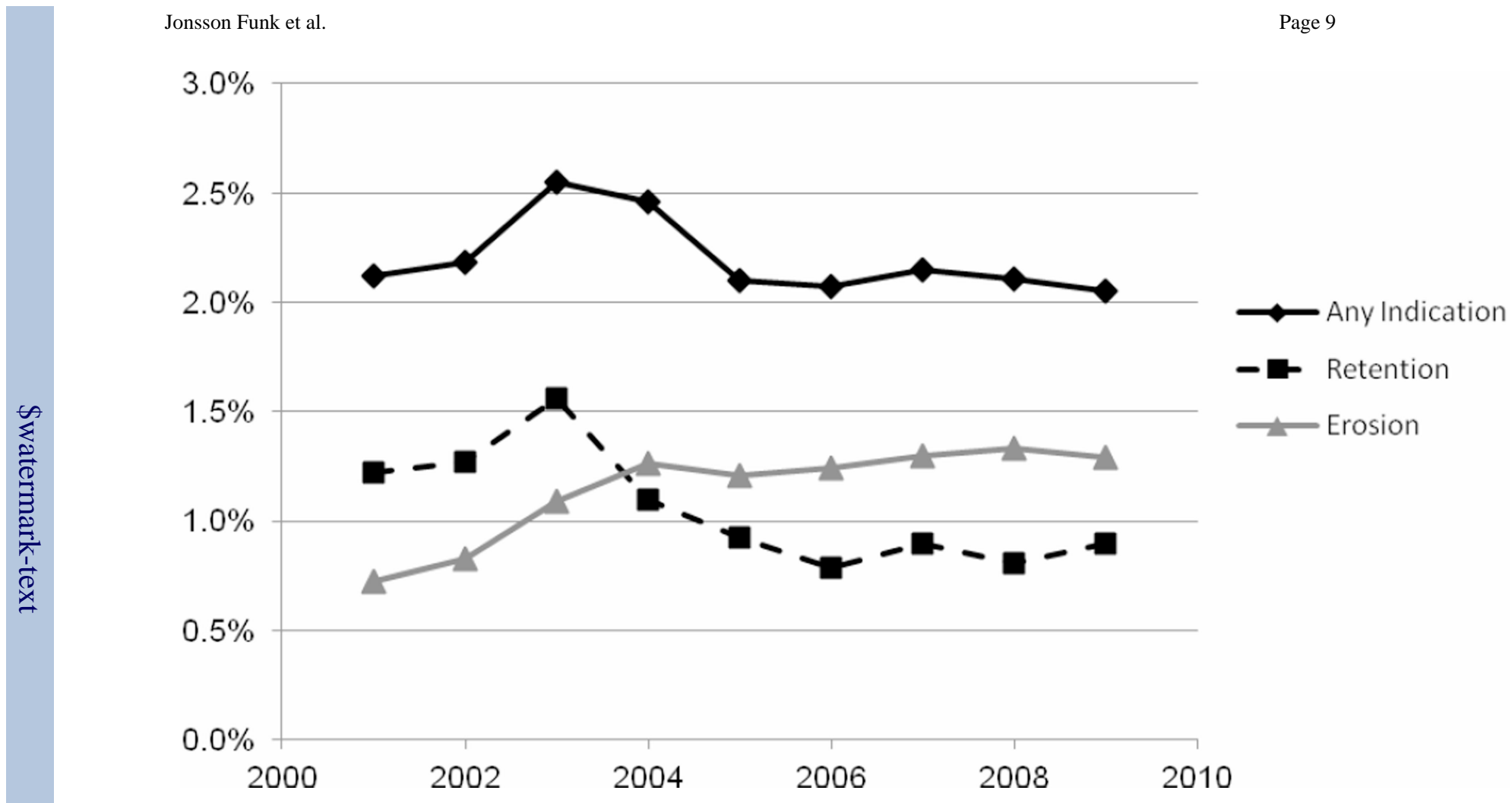

Figure 1.

Cumulative one-year risk of sling revision for any indication, retention or mesh erosion, stratified by year of index sling 
Table 1

Characteristics of Women who Underwent an Index Sling

\begin{tabular}{|c|c|c|}
\hline & $\mathrm{N}=188,454$ & $\%$ \\
\hline \multicolumn{3}{|l|}{ Age at Index Sling } \\
\hline Median (IQR) & $53(45,61)$ & -- \\
\hline Mean (SD) & 53.7 (11.9) & -- \\
\hline 18-29 years & 1,314 & 0.7 \\
\hline $30-39$ years & 18,429 & 9.8 \\
\hline $40-49$ years & 55,248 & 29.3 \\
\hline $50-59$ years & 57,208 & 30.4 \\
\hline $60-69$ years & 35,150 & 18.6 \\
\hline $70-79$ years & 16,183 & 8.6 \\
\hline $80+$ years & 4,942 & 2.6 \\
\hline \multicolumn{3}{|c|}{ Year when Index Surgery Performed } \\
\hline 2001 & 2,322 & 1.2 \\
\hline 2002 & 5,026 & 2.7 \\
\hline 2003 & 8,835 & 4.7 \\
\hline 2004 & 13,350 & 7.1 \\
\hline 2005 & 17,445 & 9.3 \\
\hline 2006 & 20,437 & 10.8 \\
\hline 2007 & 23.066 & 12.2 \\
\hline 2008 & 30,155 & 16.0 \\
\hline 2009 & 33,654 & 17.9 \\
\hline 2010 & 34,164 & 18.1 \\
\hline \multicolumn{3}{|c|}{ Time Intervals of Follow-up } \\
\hline 0 to $<2$ years & 122,213 & 64.9 \\
\hline 2 to $<4$ years & 41,022 & 21.8 \\
\hline 4 to $<6$ years & 16,827 & 8.9 \\
\hline 6 to $<8$ years & 6,528 & 3.5 \\
\hline $8+$ years & 1,864 & 1.0 \\
\hline Outpatient Index Slings & 126,443 & 67.1 \\
\hline \multicolumn{3}{|l|}{ Region } \\
\hline Northeast & 13,724 & 7.3 \\
\hline Midwest & 52,035 & 27.6 \\
\hline South & 92,145 & 48.9 \\
\hline West & 29,624 & 15.7 \\
\hline Unknown & 924 & 0.5 \\
\hline \multicolumn{3}{|l|}{ Concomitant Surgery } \\
\hline Hysterectomy & 47,065 & 25.0 \\
\hline
\end{tabular}




\begin{tabular}{|l|r|r|}
\hline & $\mathbf{N = 1 8 8 , 4 5 4}$ & \% \\
\hline Anterior prolapse procedures & 62,469 & 33.2 \\
Apical prolapse procedures & 22,743 & 12.1 \\
Posterior prolapse procedures & 13,198 & 7.0 \\
\hline
\end{tabular}


Table 2

Cumulative Risk of Sling Revision/Removal by Indication Reported by Follow-up Time after the Index Sling

\begin{tabular}{|c|c|c|c|}
\hline $\begin{array}{c}\text { Follow-up after } \\
\text { Index Sling (yr) }\end{array}$ & $\begin{array}{c}\text { Cumulative Risk of } \\
\text { Revision/Removal for } \\
\text { Urinary Retention }\end{array}$ & $\begin{array}{c}\text { Cumulative Risk of } \\
\text { Revision/Removal for } \\
\text { Mesh Erosion }\end{array}$ & $\begin{array}{c}\text { Cumulative Risk of } \\
\text { Sling Revision/Removal } \\
\text { for Any Indication }\end{array}$ \\
\hline 0.25 & $0.6(0.5,0.6)$ & $0.5(0.5,0.5)$ & $1.0(1.0,1.1)$ \\
\hline 0.5 & $0.8(0.7,0.8)$ & $0.9(0.8,0.9)$ & $1.6(1.5,1.6)$ \\
\hline 1 & $0.9(0.9,1.0)$ & $1.3(1.2,1.3)$ & $2.2(2.1,2.2)$ \\
\hline 2 & $1.1(1.0,1.1)$ & $1.6(1.6,1.7)$ & $2.6(2.5,2.7)$ \\
\hline 3 & $1.2(1.1,1.2)$ & $1.9(1.8,2.0)$ & $3.0(2.9,3.1)$ \\
\hline 4 & $1.2(1.1,1.3)$ & $2.1(2.0,2.2)$ & $3.2(3.1,3.4)$ \\
\hline 5 & $1.2(1.2,1.3)$ & $2.2(2.1,2.3)$ & $3.4(3.3,3.5)$ \\
\hline 6 & $1.3(1.2,1.4)$ & $2.3(2.2,2.4)$ & $3.6(3.5,3.7)$ \\
\hline 7 & $1.3(1.2,1.4)$ & $2.5(2.3,2.6)$ & $3.7(3.5,3.9)$ \\
\hline 8 & $1.3(1.2,1.4)$ & $2.5(2.3,2.6)$ & $3.7(3.5,3.9)$ \\
\hline 9 & $1.3(1.2,1.4)$ & $2.5(2.3,2.6)$ & $3.7(3.5,3.9)$ \\
\hline
\end{tabular}




\section{Table 3}

Cox proportional hazards regression analyses adjusting for age for time to sling revision/removal for mesh erosion, urinary retention, and any indication.

\begin{tabular}{|c|c|c|c|}
\hline & $\begin{array}{c}\text { Retention } \\
\text { Adj HR (95\% CI) }\end{array}$ & $\begin{array}{c}\text { Mesh Erosion } \\
\text { Adj HR (95\% CI) }\end{array}$ & $\begin{array}{c}\text { Any indication } \\
\text { Adj HR (95\% CI) }\end{array}$ \\
\hline \multicolumn{4}{|l|}{ Age } \\
\hline $18-29$ & $1.91(1.22,2.99)$ & $2.52(1.58,4.00)$ & $2.02(1.46,2.80)$ \\
\hline $30-39$ & $1.19(0.98,1.45)$ & $2.64(2.19,3.18)$ & $1.69(1.48,1.93)$ \\
\hline $40-49$ & $0.87(0.74,1.02)$ & $2.08(1.76,2.45)$ & $1.28(1.14,1.43)$ \\
\hline $50-59$ & $0.91(0.78,1.07)$ & $1.89(1.60,2.22)$ & $1.22(1.10,1.37)$ \\
\hline $60-69$ & $0.91(0.77,1.08)$ & $1.52(1.28,1.82)$ & $1.10(0.98,1.24)$ \\
\hline $70+(\mathrm{ref})$ & -- & -- & -- \\
\hline \multicolumn{4}{|l|}{ Procedure Location } \\
\hline Inpatient & $1.18(1.06,1.32)$ & $1.04(0.95,1.15)$ & $1.08(1.00,1.16)$ \\
\hline Outpatient (ref) & -- & -- & -- \\
\hline \multicolumn{4}{|l|}{ Concomitant Surgery $^{a}$} \\
\hline Hysterectomy & $0.98(0.87,1.10)$ & $0.81(0.73,0.90)$ & $0.84(0.77,0.91)$ \\
\hline Anterior Prolapse Surgery & $1.22(1.09,1.36)$ & $1.18(1.08,1.29)$ & $1.18(1.10,1.27)$ \\
\hline Apical Prolapse Surgery & $1.43(1.25,1.64)$ & $1.24(1.10,1.41)$ & $1.27(1.16,1.40)$ \\
\hline Posterior Prolapse Surgery & $1.02(0.85,1.23)$ & $1.06(0.91,1.24)$ & $1.06(0.94,1.20)$ \\
\hline
\end{tabular}

${ }^{a}$ Reference group includes those patients who did not have the specified procedure. 